\author{
육계 사료내 우모 Digest 첨가시 생산성과 계육내 Taurine 함량에 \\ 미치는 영향 \\ 이승민* . 임희석* · 김우연** . 백인기* \\ 중앙대학교 산업과학대학 동물자원과학과*, 생명공학과**
}

\title{
The Effects of Dietary Supplementation of Feather Meal Digests on the Performances and Muscular Taurine Contents in Broiler Chickens
}

\author{
S. M. Lee*, H. S. Lim*, W. Y. Kim**, and I. K. Paik* \\ Department of Animal Science and Technology* and Department of Biotechnology**, \\ College of Industrial Science, Chung-Ang University, Ansung-Si, Kyounggi-Do 456-756, South Korea
}

\begin{abstract}
An experiment was conducted to investigate the effects of dietary supplementation of feather meal(FM) and its digests on the performance of broiler chicks and taurine content in broiler meat. A total of 100 broiler chickens were assigned to five dietary treatments; Control, FM diet(FM), $\mathrm{NaOH}$ treated FM diet(NaOH-FM), $\mathrm{HNO}_{3}$ treated $\mathrm{FM} \operatorname{diet}\left(\mathrm{HNO}_{3}-\mathrm{FM}\right)$ and $0.5 \%$ synthetic taurine supplemented $\operatorname{diet}($ Taurine). Treated diets were supplemented with FM or FM digests at the level of $5 \%$ to the control diet. Treated diets were fed during the last 3wks of 6 wks feeding. During the finisher period, weight gain of chicks fed FM treatments tended to decrease in general. Feed intakes of FM and Taurine were significantly lower than the control but were not significantly different from $\mathrm{NaOH}-\mathrm{FM}$ or $\mathrm{HNO}_{3}-\mathrm{FM}$. Feed conversion rate(feed intake/gain) of NaOH-FM was significantly higher than those of $\mathrm{FM}$ and $\mathrm{HNO}_{3}-\mathrm{FM}$ but not different from those of the control and

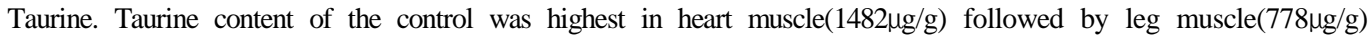
and breast muscle $(79 \mu \mathrm{g} / \mathrm{g})$. Taurine contents of leg and breast muscle were significantly $(\mathrm{P}<0.01)$ affected by treatments but that of heart muscle was not. Taurine content of Taurine treatments was highest in both leg and breast muscle. Taurine content of leg muscle was increased $170 \%$ by Taurine supplementation, $123 \%$ by FM supplementation, $122 \%$ by $\mathrm{NaOH}-\mathrm{FM}$ supplementation and $63 \%$ by $\mathrm{HNO}_{3}-\mathrm{FM}$ supplementation compared with control. Taurine content of breast muscle of Taurine treatment was $246 \%$ higher than the control, but other treatments were not different from the control. In conclusion, supplementation of feather meal at $5 \%$ level of broiler diet can enrich taurine content of leg muscle. Chemical treatments of FM were not effective in improving taurine enrichment of broiler meat.
\end{abstract}

(Key words : Taurine, Feather meal, Feather meal digest, Broiler)

$\begin{array}{cl}\text { I 서 론 } & \text { 그냥 말려서 만든 것에 비하여 소화이용율이 } \\ & \text { 높고 사료가치가 우수하나 전처리 과정에서 폐 } \\ \text { 우모분(feather meal; FM)이란 가금의 깃털을 } & \text { 수 및 악취가 강해 일종의 공해 산업으로 취급 } \\ \text { 고압하에서 가열처리하여 건조, 분쇄한 것으로 } & \text { 되고 있으며 단백질 이용율은 } 27 \text { 63\%로 아주 }\end{array}$

Corresponding author : Y. Y. Kim, School of Agricultural Biotechnology, Seoul National University, Seoul 151-742, Korea. Tel : +82-2-880-4801, Fax : +82-2-878-5839. E-mail : yooykim@snu.ac.kr. 
낮다(Moran 등, 1966; Morris와 Balloun. 1973). 생우모 단백질의 소화율은 $7.7 \%$ 였으나 우모분 단백질의 소화율은 $80 \%$ 정도 였다고 보고했다 (McCasland와 Richardson, 1966). 우모분은 조단 백질 함량이 $85 \%$ 이상 되므로 부족한 동물성 단백질을 보충할 수 있다는 것과 폐기물을 활 용한다는 면에서 볼 때 사료화의 의의가 크지 만 우모 단백질의 $85 \sim 90 \%$ 는 케라틴(Harrap와 Woods, 1964)으로 구성되어 있고, 그 구조는 $\beta$-helix를 형성하는 펩타이드 결합과 사슬내 의 수많은 수소결합을 형성하고 이들은 다시 disulfide bond에 의하여 케이블과 같이 꼬여 있 기 때문에 물리, 화학적으로 안정된 형태를 취 하고 있어 소화효소에 의해 쉽게 분해하기가 어렵다(Schor와 Krimm; 1961; Moran 등, 1966). 특히, 아미노산의 균형이 잘 이루어져 있지 않 아 methionine, lysine, histidine, tryptophan 등이 부족하다는 사실과, 우모 단백질은 소화 이용 율이 극히 낮아 이것이 사료적 가치를 떨어뜨 리는 요인이 되고 있다. McKerns와 Rittersporn (1958)에 의하면 브로일러 사료의 총단백질의 $25 \%$ 까지는 우모분으로 대치할수 있다고 보고 했으며, Lillie 등(1956)도 병아리 사료에 우모 분으로 어분을 대치할 수 있고 UGF원으로 필 요할 것이라 하였으며, 우모분의 높은 단백질 함량중에는 cysteine이 풍부하다고 보고 하였다 (Papadopoulos, 1985). 타우린(2-aminoethanesulfonic acid)은 황을 함유한 아미노산으로서 methionine 이나 cystine과 같은 아미노산 대사과정의 최종 생산물로 조직에서는 유리 아미노산의 형태로 존재하고 단백질 합성이나 에너지원으로 이용 되지 않으며 대부분의 동물조직에서 발견되는 생체내 주된 유리 아미노산이다. 따라서, 우모 분은 cystine이 가장 풍부한 원료이므로 사료에 첨가시 타우린 전구체를 공급함으로써 타우린 이 강화된 계육생산이 가능할 것으로 예상된 다. 타우린은 체내에서 함황아미노산인 cysteine 으로부터 생합성되나 인체의 경우 생합성과정 에 관여하는 효소인 cysteine dioxygenase와 cysteine sulfinate decarboxylase의 활성이 낮아 생 합성이 거의 일어나지 않으며(Rigo와 Senterre, 1977; Sturman와 Hayes, 1980), 이에 따라 타우
린이 첨가되지 않은 합성조제유를 섭취하는 미 숙아와 영아(Rassin 등, 1983), 그리고 장기간 피장(避腸)영양(total parenteral nutrition)을 받은 어린이(Vinton 등, 1987) 에게서 혈장의 타우린 수준이 감소되었고 망막전도(electroretinogram) 에 이상이 초래되었음이 보고된 바 있다. 타우 린의 대표적인 기능으로는 간장에서 콜레스테 롤로부터 합성된 담즙산과 결합하여 장관내에 서 지방분해, micell 형성 및 지방흡수를 개선 시키며(Gaull, 1983), insulin의 활력증진(Lampson 등, 1983), oxidation( $\mathrm{Li}$ 등, 1993; Trachtman 등, 1993)이나 peroxidation(Waterfield 등, 1993; Ding 등, 1993)의 생성물로부터 세포막 보호, 포유동 물의 삼투압 조절 역할(Chan과 Fishman, 1979), 신경조절작용(Arzate 등, 1986), 생식 기능의 활 성화 작용(Alvarez와 Storey, 1983), 항산화 작용 (Pasanties-Morales와 Cruz, 1984)과 해독작용 (Dorvil 등, 1983), 혈중 콜레스테롤 감소효과 (Yokogoshi 등, 1999), 혈중 glucose 감소 효과 (Nakaya 등, 2000)등 여러 가지 생리적 기능이 알려져 왔다. 또한 taurine 함량이 적거나 함유 되지 않은 사료를 고양이에게 급여시 고양이의 망막퇴행이 일어나며 유아에게 taurine이 결핍 된 유아식을 급여시 유아의 혈장과 뇨의 taurine 수준이 모유를 급여한 유아에 비해 낮다는 사실이 밝혀졌다. 따라서 본 연구에서는 taurine 의 전구물질인 cystine 공급원으로서 우모분과 이의 생체이용율을 높이기위해 산 또는 알카리 로 가공 처리하여 만든 우모분 digest를 기초사 료에 첨가하여 육계의 성장율과 계육(가슴살, 다릿살) 및 심장의 taurine 함량에 미치는 영향 을 조사하기 위하여 실시하였다.

\section{프재료 및 방법}

\section{1. 기초사료 및 처리구}

본 시험에 사용된 기초사료(대조구)의 배합 비와 성분은 Table 1에서 보는 바와 같다. 이 사료를 control로 하고 여기에 우모분(Feather meal; $\mathrm{FM}) 5 \%$ 첨가(FM), $\mathrm{NaOH}$ 처리 $\mathrm{FM}$ $5 \%$ 첨가 $(\mathrm{NaOH}-\mathrm{FM}), \mathrm{HNO}_{3}$ 처리 $\mathrm{FM} 5 \%$ 첨 
가 $\left(\mathrm{HNO}_{3}-\mathrm{FM}\right)$, 그리고 합성 타우린 $0.5 \%$ 첨가 (Taurine)한 시험사료들을 만들었다.

Table 1. Composition and nutrient content of experimental diets

\begin{tabular}{lc}
\hline Ingredients & $\%$ \\
\hline \hline Corn & 55.88 \\
Soybean meal (44\% CP) & 31.52 \\
Corn gluten meal & 3.57 \\
Animal fat & 4.00 \\
Calphos-18 & 1.70 \\
Rapeseed meal & 1.30 \\
Fish meal & 1.00 \\
Limestone & 0.38 \\
Salt & 0.20 \\
Vitamin premix & $0.15^{1)}$ \\
Mineral premix & $0.10^{2)}$ \\
Total & 100
\end{tabular}

Calculated composition

ME Poultry, kcal/kg

31.50

Crude Protein, \%

22.00

Calcium, \%

0.95

Lysine, \%

1.18

Meth \& Cyst, \%

0.90

Avail-P, \%

0.25

\section{3. 시험설계 및 사양}

사양시험을 위하여 갓부화한 brolier(Ross $\left.{ }^{\circledR}\right)$ 100 수를 공시하여 5 처리 2 반복, 반복당 10 수씩 (암.수 5수씩) 2반복으로 철제 battery(가로: $90 \mathrm{~cm}$, 세로 : $90 \mathrm{~cm}$, 높이:50cm)에 배치하였다. 사양시험은 42 일간 실시하였으며 21일령까지는 대조구사료를 모두에게 급여하였고, 처리 사료 는 22일령부터 42 일령까지 급여하였다. 시험기 간동안 물과 사료는 자유채식을 시켰다. 조명 은 24시간 점등하였고 매주 group 별로 체중과 사료섭취량을 측정하였다.

\section{Sample 채취}

사양시험 종료(42일령) 후 각 처리별로 반복 당 평균체중에 가까운 암.수 각 5수씩, 총 100 수를 도체하여 가슴살, 다릿살 그리고 심장을 채취한 후 분석시까지 $-50^{\circ} \mathrm{C}$ 에 냉동 보관하였 다.

\section{5. 타우린 분석}

타우린 분석은 Paola 와 Fillippo(1999)의 분석 방법에 준하였다. 얻어진 결과는 $\mu \mathrm{g} / \mathrm{g}$, fresh matter로 표시하였다.

\section{(1) Sample 전처리}

냉동 보관한 계육 sample과 $0.4 \mathrm{M}$ perchloric acid를 $1: 5$ 의 비율로 넣어 균질하고 난 후, $4{ }^{\circ} \mathrm{C}$ 에서 $13,000 \mathrm{rpm}$ 으로 20 분동안 원심분리하여 상층액을 수집하고 같은 과정을 2회 반복한다. 상층액 $2 \mathrm{~m} \ell$ 을 anion-exchange-column(AG 50WX8, $200 \sim 400$ mesh, $\mathrm{H}^{+}$form, $5 \times 15$ mm, BioRad Laboratories)에 통과시켰고 다시 $1 \mathrm{~m} \ell$ 의 증 류수를 3회 washing을 하여 총 $5 \mathrm{~m} \ell$ 의 추출액을 만들었다.

\section{(2) High-performance liquid chromatography} (HPLC) 시스템

분석에 사용한 HPLC는 다음과 같다; HPLC Model 305 system(Gilson, France), Fluorometer 
Model 121(Gilson, Frnace), Merck LichroCART column(Superspher 100 RP-18 end-capped, $125 \times$ $4 \mathrm{~mm}$ ID) combined with a Merck LichroCART pre-column(Lichrospher 100 RP-18, $4 \times 4$ mm ID)

(3) O-phthalaldehyde(OPA) 유도반응

추출액중 $100 \mu \ell$ 를 $\mathrm{OPA}$ 유도체와 5 분 동안 반응시킨후 column을 통과시켜 fluorometer(형광 검출기)로 측정을 하였다. $\mathrm{OPA}$ 유도체 제조: (1) $\mathrm{OPA}(25 \mathrm{mg})$ 를 methanol $(0.6 \mathrm{~m} \ell)$ 에 녹인다. (2) sodium tetraborate(404mg)를 water bath에서 HPLC water(5m $\ell)$ 에 녹인후 식힌다. (3) borate solution (2)을 OPA solution(1)에 첨가하고 2-mercap-

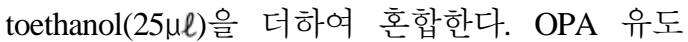
체는 제조후 $4^{\circ} \mathrm{C}$ 의 어두운곳에 보관하고 12 시 간 이내에 사용한다(Pittaluga 등, 1977).

\section{6. 통계분석}

시험에서 얻어진 자료의 통계처리는 SAS (1995)의 GLM(General Linear Model) procedure 를 이용하여 분석하였고, 처리 평균간의 차이 는 Duncan's multiple range test에 의하여 $\mathrm{P}<$ 0.01 에서 검정하였다.
III 결과 및 고찰

\section{1. 육계의 생산성}

사양시험 기간동안에 얻어진 증체량, 사료 섭취량, 사료 요구율 및 폐사율은 Table 2에 서 보는 바와 같다. 사양시험 42일중 21일령 까지는 모든 처리구에 대조구 사료를 급여하 였고, 처리 사료는 22일령부터 42일령까지 급 여하였다. 증체량에 있어 처리구들은 control 에 비해 낮았지만 유의차가 없었다. 사료 섭 취량은 Taurine과 $\mathrm{FM}$ (Feather meal) 급여구가 대조구에 비해 낮았고 $\mathrm{NaOH}-\mathrm{FM}$ 과 $\mathrm{HNO}_{3}-\mathrm{FM}$ 구들이 $\mathrm{FM}$ 구 보다는 높은 경향이 있었다. 사 료요구율은 $\mathrm{NaOH}-\mathrm{FM}$ 구가 $\mathrm{HNO}_{3}-\mathrm{FM}$ 구와 $\mathrm{FM}$ 구보다 유의하게 높았으나 대조구나 taurine구와는 유의한 차이가 없었다. Moran 등(1966)은 우모분을 양계사료의 경우에 대두 박 대신에 $5 \%$ 정도 사용해도 좋으나, 우모분 의 제한 아미노산은 methionine, lysine, tryptophan 등이라고 보고했으며, Naber등 (1961)은 병아리의 사료에 있어서 총 단백질 의 $25 \%$ 까지는 우모분으로 대치해도 아무런 장애가 나타나지 않았으며, 총사료 단백질의 $50 \%$ 이상을 대치할 경우에는 tryptophan,

Table 2. Effects of dietary feather meal and its digests on weight gain, feed intake, feed/gain and mortality in broiler chickens.

\begin{tabular}{|c|c|c|c|c|c|c|c|}
\hline \multirow{2}{*}{ Item } & \multirow{2}{*}{ wks } & \multicolumn{5}{|c|}{ Treatments $^{1)}$} & \multirow{2}{*}{ SEM } \\
\hline & & Control & FM & $\mathrm{NaOH}-\mathrm{FM}$ & $\mathrm{HNO}_{3}-\mathrm{FM}$ & Taurine & \\
\hline \multirow{3}{*}{$\begin{array}{l}\text { Weight gain, } \\
\text { g/bird }\end{array}$} & $0-3$ & 699.0 & 687.1 & 709.1 & 718.2 & 691.6 & 21.045 \\
\hline & $4-6$ & $1,465.8$ & 1,355.3 & 1,325.8 & $1,447.3$ & $1,356.8$ & 54.703 \\
\hline & $0-6$ & $2,164.8$ & $2,042.3$ & 2,034.8 & $2,165.4$ & $2,048.4$ & 36.283 \\
\hline \multirow{3}{*}{$\begin{array}{l}\text { Feed intake, } \\
\text { g/bird }\end{array}$} & $0-3$ & 973.9 & 943.0 & 942.8 & $1,021.3$ & 949.5 & 44.823 \\
\hline & $4-6$ & $2,700.4^{\mathrm{a}}$ & $2,440.0^{\mathrm{b}}$ & $2,623.5^{\mathrm{ab}}$ & $2,550.0^{\mathrm{ab}}$ & $2,492.5^{\mathrm{ab}}$ & 56.784 \\
\hline & $0-6$ & $3,674.3^{\mathrm{a}}$ & $3,383.0^{\mathrm{b}}$ & $3,566.3^{\mathrm{ab}}$ & $3,571.3^{\mathrm{ab}}$ & $3,442.0^{\mathrm{b}}$ & 70.013 \\
\hline \multirow{3}{*}{$\begin{array}{c}\text { Feed/gain } \\
\text { (g/g) }\end{array}$} & $0-3$ & 1.39 & 1.37 & 1.33 & 1.42 & 1.37 & 0.025 \\
\hline & $4-6$ & $1.84^{\mathrm{ab}}$ & $1.80^{\mathrm{ab}}$ & $1.98^{\mathrm{a}}$ & $1.76^{\mathrm{b}}$ & $1.84^{\mathrm{ab}}$ & 0.051 \\
\hline & $0-6$ & $1.69^{\mathrm{ab}}$ & $1.66^{\mathrm{b}}$ & $1.75^{\mathrm{a}}$ & $1.65^{\mathrm{b}}$ & $1.67^{\mathrm{ab}}$ & 0.022 \\
\hline Mortality, \% & $0-6$ & 0 & 0 & 0 & 0 & 0 & 0.022 \\
\hline
\end{tabular}

\footnotetext{
${ }^{a, b}$ Means in a row with no common superscript differ significantly $(\mathrm{P}<0.05)$.

${ }^{1)} \mathrm{FM}$; 5\% Feather meal diet, NaOH-FM; 5\% $\mathrm{NaOH}$ treated $\mathrm{FM}$ diet, $\mathrm{HNO}_{3}$-FM; 5\% HNO3 treated FM diet, Taurine; $0.5 \%$ Synthetic taurine supplemented diet.
} 
histidine 까지도 첨가해 주어야 한다고 보고 하였다. Moran과 Summers(1966)는 우모분이 육계에 있어 사료적 가치가 낮은 것은 lysine 과 methionine의 함량이 부족하기 때문이라고 하였다. 또한, Smith(1968)에 의하면 어분, 대 두박, 우모분에 들어 있는 아미노산의 이용 효율을 측정한 결과 우모분에 들어있는 아미 노산의 이용성은 어분이나 대두박의 그것보 다 상당히 떨어졌고 특히 histidine $(0.0 \%)$, lysine(5.3\%)의 이용성은 매우 낮아서 우모분 의 영양가를 낮게 하는 원인일 것이라고 하 였다. 본 실험에서 우모분 또는 우모 digests 첨가구의 증체율이나 사료섭취량이 낮은 것 은 이들의 이용율이 낮고 아미노산 조성이 양호하지 못하며 우모분 또는 우모 digest $5 \%$ 단순첨가로 calorie/protein ratio 균형을 깨 므로 예상되었던 바이다. Taurine의 첨가 또 는 우모분의 cystine이 체내 taurine으로 전환 되어 성장에 영향을 미치게 될거라 예상 할 수 있으나 많은 연구가들에 의하여 보고된 바에 의하면 taurine은 성장 과정중 초기에 영향을 미치는 것으로 사료된다. 타우린은 신생기 동물(neonates)의 성장에 중요한 역할 을 한다고 보고 되었고(Hayes와 Sturman 1981; Sturman, 1982; Hayes, 1985), 어린 병아리의 경우 타우린의 첨가가 지속적인 성장 증진을 야기한다는 Martin과 Patrick(1961, 1966)의 보 고와 신생기 동물에 있어서 외부로부터 타우 린 섭취의 부족은 성장을 지연시킨다는 보고 (Hayes, 1985)도 있다. 또한, Scheibel 등(1980, 1981)과 Ikuyama 등(1988)은 적정량의 타우린 이 동물의 성장에 있어서 직접적인 영향을 미치는 growth hormone과 유사한 효과를 가 지고 있는 prolactin의 방출을 촉진시킨다고 보고 하였다. Davis와 Himwich(1973)는 뇌중 타우린 농도가 뇌의 발육시기에 가장 높아졌 다가 발육과 함께 저하된다고 보고하였고 사 람(Lefauconnier 등, 1976), 원숭이(Raizada 등, 1982), mouse(Kantro 등, 1984), 토끼(Chandra 와 Himwich, 1970) 및 $\operatorname{rat}(\mathrm{Lieu}$ 등, 1992)에서 공통적으로 관찰되었다. 또한, 동물의 종류,
동물의 발달 단계, 식이내 단백질 또는 함황 아미노산의 함량에 따라 CSA 경로를 촉매하 는 두가지 효소, $\mathrm{CD}$ (cysteine dioxygenase)와 $\mathrm{CSAD}$ (cysteinesulfinate acid decarboxylase)의 활 성이 큰 차이를 보이며, 이에 따라 타우린 생 합성 능력이 크게 달라지게 되므로 육계의 성 장 과정중 22일령부터 42일령에서 taurine의 첨 가나 우모분의 단백질 첨가는 육계 후기동안의 성장률에 좋은 영향을 미치지 못한 것으로 사 료된다.

\section{2. 계육내 taurine 함량}

처리에 따른 각 부위의 taurine 함량 분석 결과는 Fig. $1 \sim 3$ 에서 보는 바와 같다. 대조구 의 taurine 함량을 보면 심장근육이 $1482 \mu \mathrm{g} / \mathrm{g}$ 으로 가장 높았고 다리근육이 $778 \mu \mathrm{g} / \mathrm{g}$ 이었고 가슴살이 $79 \mu \mathrm{g} / \mathrm{g}$ 으로 낮았다. 다리살과 가슴 살의 경우 처리간에 유의차 $(\mathrm{P}<0.01)$ 가 있었 으나 심장에서는 유의차가 없었다. 다리살의 경우 control에 비해 FM, FM digest, 합성 taurine 첨가구들의 taurine 함량이 유의하게 높았는데 대조구에 비해 Taurine 첨가구에서 는 $170 \%, \mathrm{FM}$ 첨가구는 $123 \%, \mathrm{NaOH}-\mathrm{FM}$ 첨 가구는 $122 \%$ 그리고 $\mathrm{HNO}_{3}-\mathrm{FM}$ 첨가구는 $63 \%$ 증가하였다. 가슴 근육에서는 합성 taurine 처리구가 대조구에 비해 246\% 높았지만 다른 처리구들(FM, FM digest)은 유의한 차가 없었다. 심장의 경우 다른 근육에 비해 타우 린 함량이 가장 높았으나 모든 처리구간에 유의한 차이가 없었다. 현재까지 알려진 타 우린의 생합성 경로는, cysteinesulfinate 경로 와 cysteamine 경로 두가지가 보고되었다. 대 부분의 조직에서 타우린 생합성의 주된 경로 로서 cysteine sulfinate(CSA)는 cysteine dioxygenase (CD)의 촉매작용에 의해 cysteine이 CSA로 산화된 후 다시 cysteine sulfinate acid decarboxylase(CSAD)의 촉매작용에 의해 hypotaurine으로 전환되고 cysteamine은 효소의 촉 매작용없이 taurine으로 전환되어진다. 전체적 인 타우린 생합성량의 약 $10 \%$ 미만인 cysteamine 경로는 cystine이 먼저 여러 단계의 효 


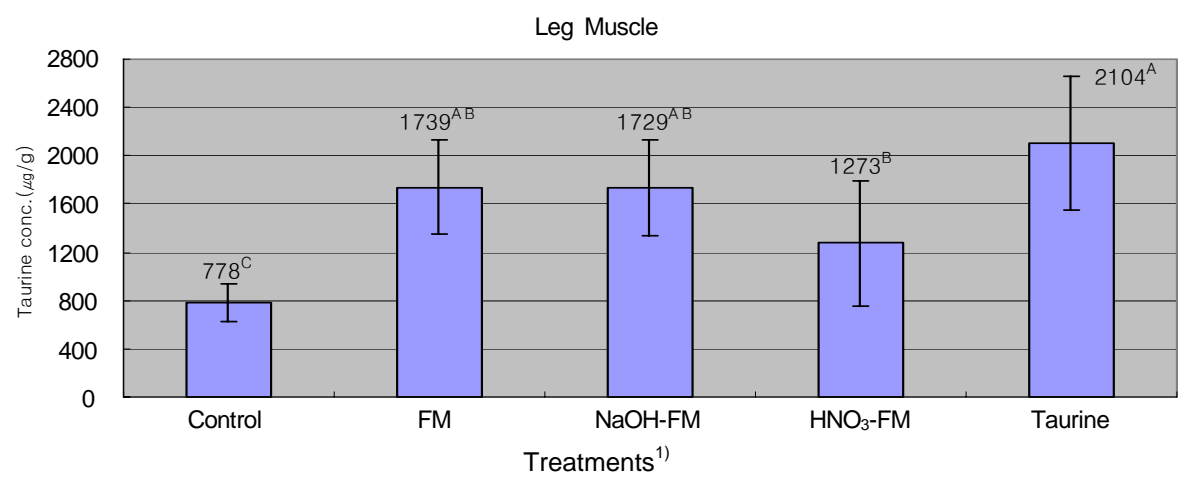

Fig. 1. Effect of dietary feather meal digests on taurine content in leg muscle of broiler chickens at 42 days of age.

${ }^{1)} \mathrm{FM}$; $5 \%$ feather meal(FM) diet, NaOH-FM; $\mathrm{NaOH}$ treated FM diet, $\mathrm{HNO}_{3}-\mathrm{FM}$; $\mathrm{HNO}_{3}$ treated FM diet, Taurine; $0.5 \%$ synthetic taurine supplemented diet.

${ }^{A-C}$ Means with no common superscript differ significantly $(\mathrm{P}<0.01)$.

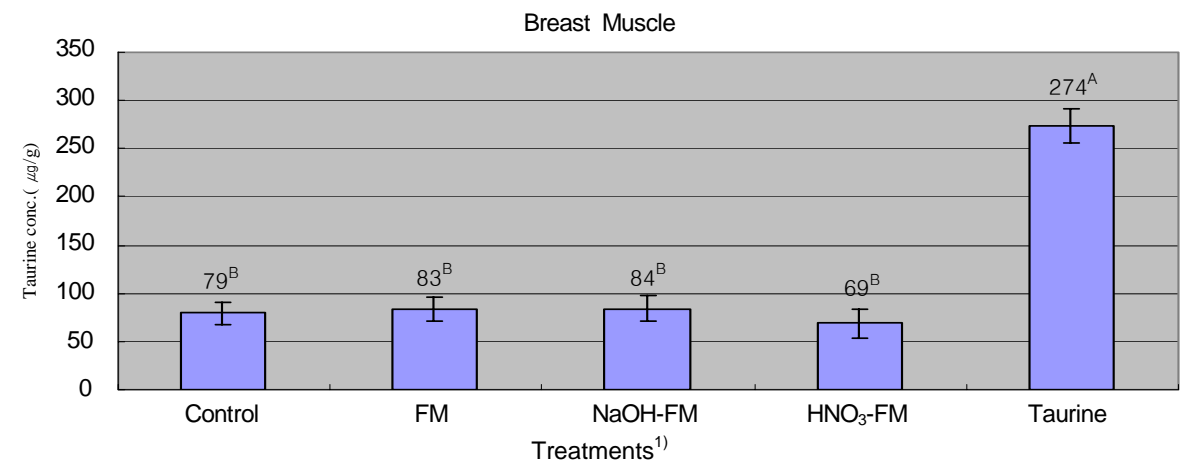

Fig. 2. Effect of dietary feather meal digests on taurine content in breast muscle of broiler chickens at 42 days of age.

${ }^{1)} \mathrm{FM}$; $5 \%$ feather meal(FM) diet, $\mathrm{NaOH}-\mathrm{FM}$; $\mathrm{NaOH}$ treated $\mathrm{FM}$ diet, $\mathrm{HNO}_{3}$-FM; $\mathrm{HNO}_{3}$ treated FM diet, Taurine; $0.5 \%$ synthetic taurine supplemented diet.

${ }^{\mathrm{A}-\mathrm{B}}$ Means with no common superscript differ significantly $(\mathrm{P}<0.01)$.

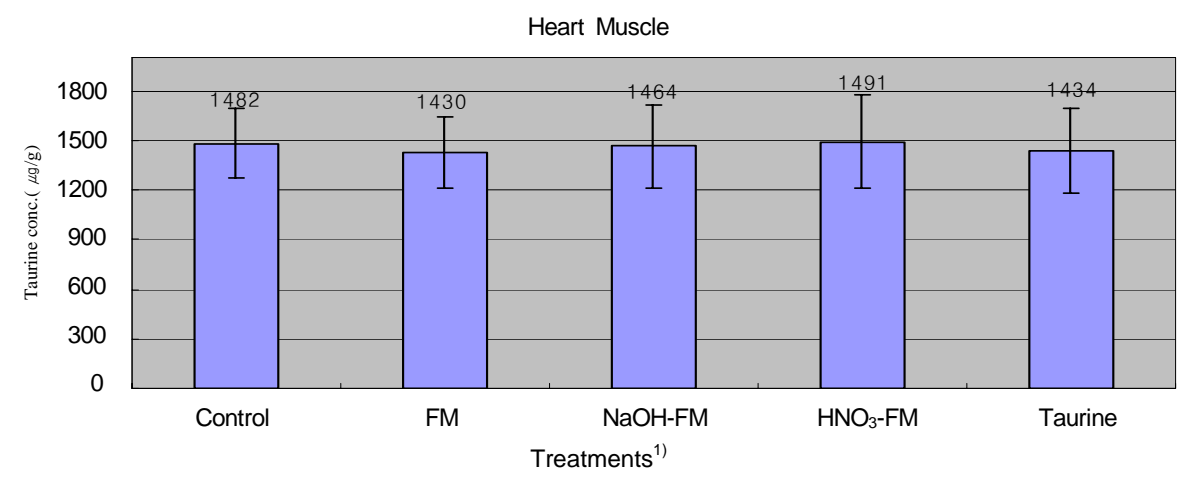

Fig. 3. Effect of dietary feather meal digests on taurine content in heart muscle of broiler chickens at 42 days of age.

${ }^{1)} \mathrm{FM}$; 5\% feather meal(FM) diet, $\mathrm{NaOH}-\mathrm{FM}$; $\mathrm{NaOH}$ treated $\mathrm{FM}$ diet, $\mathrm{HNO}_{3}-\mathrm{FM} ; \mathrm{HNO}_{3}$ treated FM diet, Taurine; $0.5 \%$ synthetic taurine supplemented diet. 
소 작용을 거쳐 cysteamine으로 전환된 후 hypotaurine과 taurine으로 대사되는 경로이다. Cystine은 병아리의 간에서 $\mathrm{CSAD}$ 의 작용에 의해 taurine으로 합성된다고 보고되었다(Jacobson과 Smith, 1968). Taurine의 생합성에 중요 한 key enzyme인 $\mathrm{CD}$ 및 $\mathrm{CSAD}$ 는 생체조직이 나 동물의 종에 따라 타우린 생합성 능력이 크게 달라지게 되고 특히, $\mathrm{CSAD}$ 의 경우 쥐 또는 개에 비해 인간을 비릇하여 원숭이, 고 양이과 동물에서 월등히 낮기 때문에 이러한 동물에 있어서 타우린 합성능력이 크게 제한 되어 있다고 보고 되었으며(Worden과 Stipanuk, 1985; Chapman과 Greenwood, 1988), 동일 종 류의 동물내에서도 $\mathrm{CD}$ 및 $\mathrm{CSAD}$ 활성은 식 이내 단백질 또는 함황아미노산의 함량에 따 라 활성이 크게 조절되는 것으로 보고되었다 (Jerkins등, 1989). 또한, 동물의 발달 단계에 따라서도 차이가 있어서 태아기 또는 어린 쥐의 경우 간과 두뇌의 $\mathrm{CD}$ 및 $\mathrm{CSAD}$ 활성이 성인 쥐의 약 $20 \%$ 정도로 매우 낮다(Sturman 과 Gaull, 1975). 육계에 있어서 근육 부위에 따른 taurine 함량에는 큰 차이가 있었는데 불 수의근이며 백색육인 가슴살은 수의근이자 적색육인 다리살에 비해 $1 / 10$ 정도 이었다. 심장근육내 taurine 함량이 가장 높았는데 처 리에 의해 영향을 받지 않았다. 심장근육내 taurine 함량이 감소시 칠면조에서 심근장애 (Schaffer 등, 1982)가 발생하였고, 육계의 급 사증과 관련하여 육골분 급여시 발생율이 감 소 하므로 심장근육내 taurine 함량과의 유관 성을 조사 하였으나 육계의 급사증과 심장근 육내 taurine 함량과는 관련이 없는 것으로 밝 혀졌다(Jacob 등, 1991).

이상의 결과들을 종합적으로 고찰해 보면 육계후기에 우모분이나 taurine을 추가적으로 공급하면 생산성은 개선되지 않으나 다리근 육내 taurine 함량을 유의하게 증가시킬수 있 다. 타우린 함량은 근육부위간에 큰 차이가 있는데 가장 함량이 높은 심장근육은 처리에 의해 유의한 영향을 받지 않으며 다리 근육 에는 가슴근육보다 약 10 배의 taurine이 함유
되어 있고 $5 \%$ 우모분 처리에 의해 taurine 함 량이 $170 \%$ 강화되었다. 한편, 우모분을 $\mathrm{NaOH}$ 와 $\mathrm{HNO}_{3}$ 로 처리하는 것은 taurine 강화에 도움이 되지 않았다.

\section{IV 요 약}

우모분(FM)과 우모분 digests가 육계의 성장 률과 계육(가슴살, 다릿살) 및 심장의 taurine 함량에 미치는 영향을 조사하기 위해 갓 부 화한 Ross ${ }^{\circledR}$ 병아리 100 수를 5 처리 2 반복 반 복당 10수씩(암.수 5수씩) 배치하여 6주간 사 양시험을 실시하였다. 시험사료는 기초사료 (control)에 $\mathrm{FM} \mathrm{5 \%}$ 첨가사료(FM), $\mathrm{NaOH}$ 처리 $\mathrm{FM} 5 \%$ 첨가사료( $\mathrm{NaOH}-\mathrm{FM}), \mathrm{HNO}_{3}$ 처리 $\mathrm{FM}$ $5 \%$ 첨가사료 $\left(\mathrm{HNO}_{3}-\mathrm{FM}\right)$ 그리고 합성 타우린 $0.5 \%$ 첨가사료(Taurine)를 시험사료로 공시하 여 42일간 실시하였으며 21일령까지는 대조 구사료를 모두에게 급여하였고, 처리 사료는 22일령부터 42 일령까지 급여하였다. 증체량에 있어 처리구들은 control에 비해 낮았지만 유 의차가 없었다. 사료 섭취량은 Taurine과 FM 급여구가 대조구에 비해 낮았고 $\mathrm{NaOH}-\mathrm{FM}$ 과 $\mathrm{HNO}_{3}-\mathrm{FM}$ 구들이 $\mathrm{FM}$ 구 보다는 높은 경향이 있었다. 사료요구율은 $\mathrm{NaOH}-\mathrm{FM}$ 구가 $\mathrm{FM}$ 과 $\mathrm{HNO}_{3}-\mathrm{FM}$ 구 보다 유의하게 높았고 대조구와 Taurine구와는 유의한 차이가 없었다. 대조구 의 taurine 함량을 보면 심장근육이 $1482 \mu \mathrm{g} / \mathrm{g}$ 으로 가장 높았고 다리근육이 $778 \mu \mathrm{g} / \mathrm{g}$ 이었고 가슴살이 $79 \mu \mathrm{g} / \mathrm{g}$ 으로 낮았다. 다리살과 가슴 살의 경우 처리간에 유의차 $(\mathrm{P}<0.01)$ 가 있었 으나 심장에서는 유의차가 없었다. 다리살의 경우 control에 비해 처리구들의 taurine 함량 이 유의하게 높았는데 Taurine 첨가구에서는 $170 \%, \mathrm{FM}$ 구는 $123 \%, \mathrm{NaOH}-\mathrm{FM}$ 구는 $122 \%$ 그 리고 $\mathrm{HNO}_{3}-\mathrm{FM}$ 구는 $63 \%$ 높았다. 가슴 근육의 타우린 함량은 Taurine구가 타처리구들에 비 해 유의하게 높았고 대조구에 비해서는 $246 \%$ 높았다. 심장의 경우에는 처리구들간에 차이 가 없었다. 결론적으로 육계후기 사료에 우모 분을 $5 \%$ 첨가했을때, 다리근육의 타우린 함량 
은 효과적으로 강화시킬수 있었으며 우모분

을 $\mathrm{NaOH}$ 나 $\mathrm{HNO}_{3}$ 로 처리하는 것은 taurine 강 화에 도움이 되지 않았다.

(색인어 : 우모분, 우모가수분해물, 타우린, 육계)

\section{$\mathrm{V}$ 인 용 문 헌}

1. Alvarez, J. G. and Storey, B. T. 1983. Taurine, hypotaurine, epinephrine and albumin inhibit lipid peroxidation in rabbit spermatozoa and protect against loss of motility. Biol. Oct. 29(3):548-55.

2. Arzate, M. E., Moran, J. and Pasantes-Morales, H. 1986. Inhibitory effect of taurine on 4-amino-pyridine-stimulated release of labelled dopamine from striatal synaptosomes. Neuropharmacology. Jul. 25(7): 689-94.

3. Chan, P. H. and Fishman R. A. 1979. Elevation of rat brain amino acids, ammonia and idiogenic osmoles induced by hyperosmolality. Brain Res 161:293.

4. Chandra. R. and Himwich, W. A. 1970. Taurine levels in developing rabbit brain and other organs. Dev. Psychobiol. 3:191-196.

5. Chapman, G. E. and Greenwood C. E. 1988. Taurine in nutrition and brain dvelopment. Nutr Res 8:955-968.

6. Davis, J. M. and Himwich, W. A. 1973. Amino acids and proteins of developing mammalian brain. In:Biochemistry of the Developing Brain, edited by W. A. Himwich. New York: Dekker, pp. 55-110.

7. Ding W. G., Tooyama. I., Kimura H., Kuriyama, K. and Ochi, J. 1993. Distribution of taurine-like immunoreactivity in the mouse liver during ontogeny and after carbon tetrachloride or phenobarbital intoxicatin. Histochem. J. 25:376-383.

8. Dorvil, N. P. I., Yousef, B. and Tuchweber, B. 1983. Taurine prevents cholestasis induced by lithocholic acid sulfate in guinea pig. Am. J. Clin. Nutr. 37:221-223.

9. Gaull, G. E. 1983. Taurine in human milk: growth modulater or onditionally essential amino acid. J. Pediat. Gastroent. Nutr. 21(suppl. 1):5266-5271.

10. Harrap, B. S. and Woods, E. F. 1964. Soluble derivatives of feather keratin: I. Isolation, fractionation amino acid composition. Biochem. J. 92:8.

11. Hayes K. C. and Sturman J. A. 1981. Taurine deficiency: a rational for taurine depletion. Adv. Exp. Med Biol. 139:79-87.
12. Hayes K. C. 1985. Taurine requirment in primates. Nutr. Rev. 43:65-70.

13. Ikuyama, S., Lkajima, T., Kato, K. I. and Ibayashi, H. 1988. Effect of taurine on growth hormone and prolactin secretion in rats: possible interaction with opioid peptidergic system Life Sci. 43:807-812.

14. Jacobsen, J. G. and Smith L. H. 1968. Biochemistry and physiology of taurine and taurine derivatives. Physiol Rev 48:424-511.

15. Jacob, J. P., Blair, R. and Hart, L. E. 1991. The effect of taurine transport antagonists on cardiac taurine concentration and the incidence of sudden death syndrome in male broiler chickens. Poult. Sci. 70:561-567.

16. Jerkins A. A, Bobroff L. E. and Steele, R. D. 1989. Hepatic cysteine sulfinic acid decarboxylase activity in rats fed various levels of dietary casein. J Nutr 119:1593-1597.

17. Kantro, P., Marnela, K. M. and Oja, S. S. 1984. GABA, Taurine and hypotaurine in developing mouse brain. Acta Physiol. Sound. Suppl. 537: 71-74.

18. Lampson, W. G., Kramer, J. H. and Schaffer, S. W. 1983. Potentiation of the actions of insulin by taurine. Can. J. Physiol. Pharmacol. 61:457-463.

19. Lefauconnier, J., Portemer, C. and Chatagner, F. 1976. Free amino acids and related substances in human glial tumours and in fetal brain: comparison with normal adult brain. Brain Res. 117:105-113.

20. Li J, Foote R. H. and Simkin M. 1993. Development of rabbit zygotes cultured in protein-free medium with catalase, taurine, or superoxide dismutase. Biol Reprod. 49:33-37.

21. Lieu, P. L., Croswell, S. and Huxtable, R. J. 1992. Phospholipids, Phospholipid methylation and taurine content in synaptosomes of developing rat brain. In: Taurine, Eds., J. B. Lombardini, W. S. Stephen, A. Azuma. pp. 399-404.

22. Lillie, R. J., Sizemore, J. R. and Denton, C. A. 1956. Feather meal in chick nutrition. Poultry Sci. 35:316-318.

23. Martin W. G. and Patrick, H. 1961. The effect of taurine on the sulfate-S35 retention in chicks. Poult. Sci. 40:267-268.

24. Martin, W. G. and Patrick, H. 1966. The incorporation of S3504 into bile of chick. Proc. Soc. Exp. Biol. Med. 121-414-417.

25. McCasland, W. E. and Richardson, L. R. 1966. Methods for determining the nutritive value of feather meals. Poultry Sci. 45:1231-1236. 
26. McKerns, K. W. and Rittersporn, E. 1958. The nutritional significance of processed keratin in poultry feeding. Poultry Sci. 37:433-436.

27. Moran, E. T. Jr., Summers, J. D. and Slinger, S. J. 1966. Amino acid inbalance : The cause for inferior performance of chicks fed feather meal rations. Poultry Sci. 45:1107.

28. Moran, E. T. Jr., Summers, J. D. and Slinger, S. J. 1966. Keratin as sources of protein for the growing chicks. 1. Amino acid inbalance as the cause for inferior performance of feather meal and the implication of disulfide bonding in raw feather as the reason for digestibility. Poultry Sci. 45:12571266.

29. Morris, W. C. and Ballounm, S. L. 1973. Effect of processing methods on the utilization of feather meal by broiler chicks. Poultry Sci. 52:858.

30. Naber, E. C., Toucjburn, S. P., Barnett, B. D. and Morgan, C. L. 1961. Effect of processing methods and amino acid supplementation of feather protein on dietary utilization by the chick. Poultry Sci. 1234-1245.

31. Nakaya, T., Minami, A., Harada, N., Sakamoto, S., Niwaand, Y. and Ohnaka, M. 2000. Taurine improves insulin sensitivity in the atsuka long-evanstokushima fatty rat, a model of spontaneous type 2 diabetes. Am. J. Clin. Nutr. 71(1):54-58.

32. Paola Zunin. and Filippo Evangelisti. 1999. Determination of free amino acids in infant formulas. International Dairy Journal. 9:653-656.

33. Papadopoulos M. C, E. l., Boushy A. R. and Ketelaars, E. H. 1985. Effect of different processing conditions on amino acid digestibility of feather meal determined by chick assay. Poultry Sci 64: 1729-1741.

34. Pasantes-Morales, H. and Cruz, C. 1984. Protective effect of taurine and zinc on peroxidation induced damage in photoreceptor outer segments. J. Neuros. Res. 11:303-311.

35. Pittaluga, A., Bonfanti, A. and Raiteri, M. 1997. Differential desensitization of ionotropic nonNMDA receptors having distinct neuronal location and function. Naunyn-Schmiedeberg' Archiv fur Pharmakologie, 356:29-38.

36. Raizada, M. K., Sturman, J. A. and Gaull, G. E. 1982. Sulfur amino acid metabolism in the developing rhesus monkey brain: interrelationship of taurine and glutamate. Neurochem. Res. 7:11071118.

37. Rassin, K., Gaull, G. E., Jarvenpaa, A. L. and
Raiha, N. C. R. 1983. Feeding the low-birth-weight infant. II. Effect of taurine and cholestrol supplementation on amino acids and cholesterol. pediatrics, 71:179.

38. Rigo, J. and Scenterre, J. 1977. Is taurine essential for the neonates? Biol. Neonates, 32:73.

39. SAS Institute Inc, 1995. SAS Users Guide: Statistics. Version 6.12 Edition. SAS Institute Inc., Cary, NC.

40. Schaffer, S. W., Czarnecki, C. M. and McClure, J. 1982. Role of taurine in furazolidone-induced cardiomyopathy. Comp. Biochem. Physiol. 72C:137140.

41. Scheibel, J., Elsasser, T. and Ondo, J. G. 1980. Stimulation of prolactin secretion by taurine, a neurally depressant amino acid. Neuroendocrinol. 30: 350-354.

42. Scheibel, J, Elsasser, T. and Ondo, J. G. 1981. Aneuromodulatory role for taurine in controlling prolactin secretion in female rats. Psychroneuoendocrinol. 6:139-144.

43. Schor, R. and Krimm, S. 1961. Studies on the structure of feather keratin $I I$. A B-helix model for the structure of feather keratin. Biophysical J. 1:489.

44, Sturman, J. A. and Gaull, G. E. 1975. Taurine in the brain and liver if the developing human and monkey. J Neurochem 25:831-835.

45. Smith, R. E. 1968. Assement of the availability of amino acids in fish meal, soybean meal and feather meal by chick growth assay. Poultry Sci. 47: 1624-1630.

46. Sturman, J. A. and Hayes, K. C. 1980. The biology of taurine in nutrition and development. In Harold HD(ed) Advances in Nutritional Research, vol 3, New York: Plnum Press, 3:231.

47. Sturman, J. A. 1982. Taurine in nutrion research. sulfur amino acid. 5:53-65.

48. Trachtman, H., Futterweit, S. and Bienkowski, R. S. 1993. Taurine prevents glucose-induced lipid peroxidation and increased collagen production in cultured rat mesangial cells. Biochem Biophys Res. Commun. 191:759-765.

49. Vinton, N. E., Laidlaw, S. A., Ament, M. E. and Kopple, J. D. 1987. Taurine concentrations in plasma, blood cells, and urine of children undergoing long-term total parenteral nutrition. Pediatr. Res., 21:399.

50. Waterfield, C. J., Turton, J. A., Scales, M. D. and Timbrell, J. A. 1993. Investigations into the effects 
of various hepatotoxic compounds on urinary and liver taurine levels in rats. Arch Toxicol 67: 244-254.

51. Worden, J. A. and Stipanuk, M. H. 1985. A comparison by species, age and sex of cysteinsulfinate decarboxylase activity and taurine concentration.
Comp Biochem Physiop. 82B:233-239.

52. Yokogoshi, H., Mochizuki, H., Nanami, K., Hida, Y., Miyachi, F. and Oda, H. 1999. Dietary taurine enhances cholesterol degradation and reduces serum and liver cholesterol concentrations in rats fed a high-cholesterol diet. J. Nutr. 129(9):1705-1712.

(접수일자 : 2004. 7. 30./ 채택일자 : 2004. 10. 21.) 
Lee et al. ; Taurine Enriched Broiler Meat

Taurine conc. $(\mu \mathrm{g} / \mathrm{g}) \quad$ Taurine conc. $(\mu \mathrm{g} / \mathrm{g})$

Taurine conc. $(\mu \mathrm{g} / \mathrm{g})$ 